\title{
MATURAÇÃO FISIOLOGICA DO COLMO E DA SEMENTE DE SORGO SACARINO
}

\section{RAMIRO VILELA DE ANDRADE ${ }^{1}$ e ANTONIO CARLOS DE OLIVEIRA ${ }^{2}$}

RESUMO. No processamento do sorgo sacarino pelas indústrias, somente os colmos têm sido utilizados na fabricação de álcool, enquanto que as panículas são descartadas ou aproveitadas na alimentação animal. Com o objetivo de investigar a possibilidade de um aproveitamento dos grãos como sementes, três cultivares de sorgo sacarino, BR 501, BR 503 e BR 505 foram testadas em Sete Lagoas, MG. Utilizaram-se 7 épocas de colheita, que se iniciaram 15 dias após o florescimento. A maturidade fisiológica dos colmos e das sementes das três cultivares, ocorreu quando as sementes estavam com a umidade variando de 30 a $33 \%$ correspondente ao intervalo de 35 a 44 dias após o florescimento. Neste estágio, houve maiores índices de extração de açúcar e também maior índice de germinação e vigor da semente. Com exceção da BR 501, no ano de 1985, as demais cultivares acusaram até o final do experimento (58 dias após o florescimento) um rendimento de açúcar extraído superior a $8 \%$, que é considerado o limite mínimo econômico para a utilização industrial. Concluiuse que para as cultivares estudadas, as panículas podem ser utilizadas para a produção de sementes, quando sua umidade estiver próxima dos $30 \%$.

Termos para in dexação: Sorghum bicolor, poder germinativo, vigor, extração do caldo, extração de açúcar, fibra.

\section{PHYSIOLOGICAL MATURATION OF THE STALK AND THE SEED OF SACCHARINE SORGHUM}

ABSTRACT. During processing of sweet sorghum by industry only the stalks have been used to produce alcohol, while the panicles are discharged or sometimes used for livestock feed. In order to investigate a possibility of using grain as seed, three

1 Eng. agro, MSc. EMBRAPA/CNP-Milho e Sorgo. Caixa Postal 151 - CEP 35700 - Sete Lagoas, $\mathrm{MG}$.

2 Eng. agro, Dr. EMBRAPA/CNP-Milho e Sorgo. Caixa Postal 151 - CEP 35700 - Sete Lagoas, $M G$. 
cultivars of saccharine sorghum BR 501, BR 503 and BR 505 were tested in the years of 1985 and 1986 in Sete Lagoas, MG. Seven harvesting dates were tested, spaced seven days one from the next beginning 15 days after blooming.

Physiological maturity of the seeds and the stalks occurred when seed moisture content was 30 to $33 \%$ wet basis, correspondet to 35 ato 44 days after blooming. In this stage, the greater sugar extraction, germination index and vigor were observed. Only the cultivar BR 501 in the year of 1985 , did not reach a minimum of $8 \%$ sugar extraction considered the economic limit for industrial uses. The panicles of the three cultivars of sweet sorghum tested, could be used for seed when moisture content is in the range of $30 \%$ to $33 \%$.

Index terms: Sorghum bicolor, germination index, vigor, juice extraction, sugar extraction and fiber.

\section{INTRODUÇÃO}

Durante a crise energética mundial, causada pela elevação do preço do petró. leo, o Brasil começou a pesquisar fontes alternativas de energia, encontrando na cana-de-açúcar a principal matéria prima para produção de álcool etilico. No contexto de produção de bioenergia, o sorgo sacarino constituiu-se uma outra alternativa viável para produção de álcool.

No ano de 1977, o Centro Nacional de Pesquisa de Milho e Sorgo (CNPMS) incluiu no seu programa de melhoramento, trabalhos com sorgo sacarino visando a produção de bioenergia. Foram desenvolvidas novas cultivares de sorgo sacarino adaptadas às condiçðes brasileiras, com rendimentos superiores àquelas originárias dos E.U.A. (Schaffert, 1986).

Durante o processamento do sorgo sacarino pelas indístrias, somente os colmos têm sido utilizados na fabricação do álcool. As panículas com os grãos são descartados e em alguns casos, aproveitados na alimentação animal.

Koleman \& Stokes (1964), trabalhando com sorgo sacarino, concluíram que as cultivares "Sart" e "Wiley" poderiam ser utilizadas na produção de melaço, no estádio compreendido entre o florescimento e o de grãos duros. Neste período, houve um aumento do Brix, com a extração do caldo permanecendo constante, aumentando consequentemente o rendimento do açúcar.

Martin et al. citado por Ventre \& Byall (1937), estudando a condutividade específica dos fluídos do tecido de sorgo sacarino, constataram um maior acúmulo de açúcar a partir do estágio de grãos duros, até a maturidade fisiológica das sementes.

Em algumas cultivares o período de utilização industrial é bastante longo. Schaffert (1986), estudando o período útil de industrialização do sorgo sacarino 
(PUI) para algumas cultivares, concluiu que este pode ser expresso pela quantidade de açúcares extraídos e que o mínimo aceitável, é de $80 \mathrm{~kg}$ de açúcar extraídos por tonelada de colmo. Este período é em média de 21 dias, podendo chegar, no caso da cultivar BR 505 , até a 56 dias.

Não foram encontrados na literatura consultada, trabalhos visando estudar o período de maturação do colmo do sorgo sacarino associado à maturação das sementes.

Sales (1978) e Maiti et al. (1985), conseguiram a germinação de sementes de sorgo à partir do 9 ? e $12^{\circ}$ dia após a antese, respectivamente. No entanto, algumas cultivares só conseguiram germinar 30 a 35 dias após a antese durante a formação da camada preta. (Maiti et al. 1985).

Com o objetivo de estudar a possibilidade de aproveitamento dos grãos de sorgo sacarino como sementes, durante a utilização dos colmos pela indústria alcooleira, três cultivares de sorgo sacarino foram testadas em Sete Lagoas, MG; nos anos de 1985 e 1986.

\section{MATERIAL E MÉTODOS}

As cultivares testadas foram: BR 501 (Brandes), BR 503 (Theis) e BR 505 (Wray). Os plantios foram realizados nos meses de dezembro de 1984 e 1985.

0 delineamento experimental foi blocos casualizados com parcelas subdivididas com 4 repetiçбes. As 3 cultivares foram dispostas nas parcelas e as 7 épocas de colheita, constituiram as subparcelas. As colheitas, espaçadas de 7 dias, iniciaram-se 15 dias após o in ício do florescimento, que foi estabelecido quando $50 \%$ das paniculas estavam emergidas. No ano de 1986 , foi suprimida a última colheita uma vez que- os colmos se encontravam muito secos, devido a ocorrência de uma estiagem prolongada no período. (Tabela 1).

Foram realizadas colheitas manuais com o aproveitamento dos colmos compreendidos entre a inserção da folha bandeira e $10 \mathrm{~cm}$ acima do solo. Os colmos foram despalhados e enviados ao laboratório e após serem triturados, foram prensados numa hidráulica a $245 \mathrm{kgf} / \mathrm{cm}^{3}$ por minuto. Esta pressão corresponde a extração a que os colmos são submetidos nas micro e mini destilarias, existentes no mercado (Schaffert, 1986). Foram determinadas as porcentagens de extração do caldo, fibra e açúcares extraídos.

As panículas provenientes dos colmos enviados para prensagem foram debulhadas a mão, imediatamente após a colheita e parte das sementes submetidas ao teste de umidade. As restantes foram secadas ao sol, peneiradas e embaladas em sacolas de papel, armazenadas em câmara fria $\left(10^{\circ} \mathrm{C}\right)$ e seca $(30 \%$ UR) por um período de 3 a 6 meses. 
Dentro deste periodo foram realizados os testes de peso de 1.000 sementes $^{1}$, germinação padrão, indice de velocidade de emergência, envelhecimento precoce ou Hoppe $^{2}$. A realizaç̃̃o dos testes foi de acordo com Brasil (1980), Maguire (1962), Zink (1970) e Hoppe (1955).

As variáveis extração do caldo, germinação, envelhecimento precoce ou Hoppe, umidade da semente, peso de 1.000 sementes, fibra, açúcares extraídos e velocidade de emergência, foram ajustadas através de um modelo de regressão quadrático em função das datas de colheita.

\section{RESULTADOS E DISCUSSÃO}

Os resultados para as cultivares BR 501, BR 503, BR 505, estão apresentados nas Figuras 1 e 2, 3 e 4, 5 e 6, respectivamente. Na Tabela 1 estão os dados climáticos correspondentes ao período de realização das colheitas.

TABELA 1. Dados climáticos do CNPMS, Sete Lagoas, MG, relativos aos periodos de realização das collheitas de sorgo sacarino, nos anos de 1985 e 1986 , respectivamente.

\begin{tabular}{|c|c|c|c|c|c|}
\hline Período & & $\begin{array}{c}\text { Precipitação } \\
\text { mm }\end{array}$ & $\begin{array}{c}\text { Evapotrans- } \\
\text { piração } \\
\mathrm{mm}\end{array}$ & $\begin{array}{c}\text { Temperatura } \\
\text { Média Mensal } \\
{ }^{\circ} \mathrm{C}\end{array}$ & $\begin{array}{c}\text { Umidade Relativa } \\
\text { Média Mensal } \\
\%\end{array}$ \\
\hline $\begin{array}{l}21 \text { a } 31.03 .85 \\
01 \text { a } 10.04 .85 \\
11 \text { a } 20.04 .85 \\
21 \text { a } 30.04 .85 \\
01 \text { a } 02.05 .85 \\
\text { Total }\end{array}$ & $\cdot$ & $\begin{array}{r}98,5 \\
2,6 \\
17,1 \\
0,0 \\
13,6 \\
131,8\end{array}$ & $\begin{array}{r}24,3 \\
25,3 \\
22,3 \\
26,2 \\
5,0 \\
103,1\end{array}$ & $\begin{array}{l}23,0 \\
21,3 \\
19,3\end{array}$ & $\begin{array}{l}74 \\
76\end{array}$ \\
\hline $\begin{array}{l}05 \text { a } 10.03 .86 \\
11 \text { a } 20.03 .86 \\
21 \text { a } 31.03 .86 \\
01 \text { a } 10.04 .86 \\
11 \text { a } 16.04 .86 \\
\text { Total }\end{array}$ & & $\begin{array}{r}15,5 \\
0,0 \\
5,5 \\
0,0 \\
11,3 \\
32,3\end{array}$ & $\begin{array}{r}26,7 \\
33,6 \\
31,8 \\
26,7 \\
18,3 \\
137,5\end{array}$ & $\begin{array}{l}23,3 \\
22,0\end{array}$ & $\begin{array}{l}71 \\
70\end{array}$ \\
\hline
\end{tabular}

1

Optou-se pelo teste de peso de 1.000 sementes em substituição ao seu peso seco uma vez que estas ficaram armazenadas em câmara fria e seca durante o período variando de 3 a 6 meses, tempo suficiente para que houvesse a estabilização da umidade, permanecendo esta constante em todas as amostras.

2 A câmara de envelhecimento precoce apresentou problemas no ano de 1986 , sendo teste substituído pelo teste de Hoppe, adaptado para sorgo, que consistiu em utilizar para cada tratamento, 4 repetições de 100 sementes que foram colocadas em folhas duplas de papel toalha. Sobre as sementes foi colocada uma fina camada de solo $( \pm 3 \mathrm{~mm})$ proveniente de um campo cultivado com sorgo por vários anos. Em cobertura, colocou-se uma folha de papel toalha, fazendo-se os rolos que form levados para uma incubadora a $10^{\circ} \mathrm{C}$ por um periodo de 10 dias. Após a incubação, os rolos foram transferidos para um germinador a $30^{\circ} \mathrm{C} \mathrm{du-}$ rante 3 dias e em seguida anotada a germinação. 


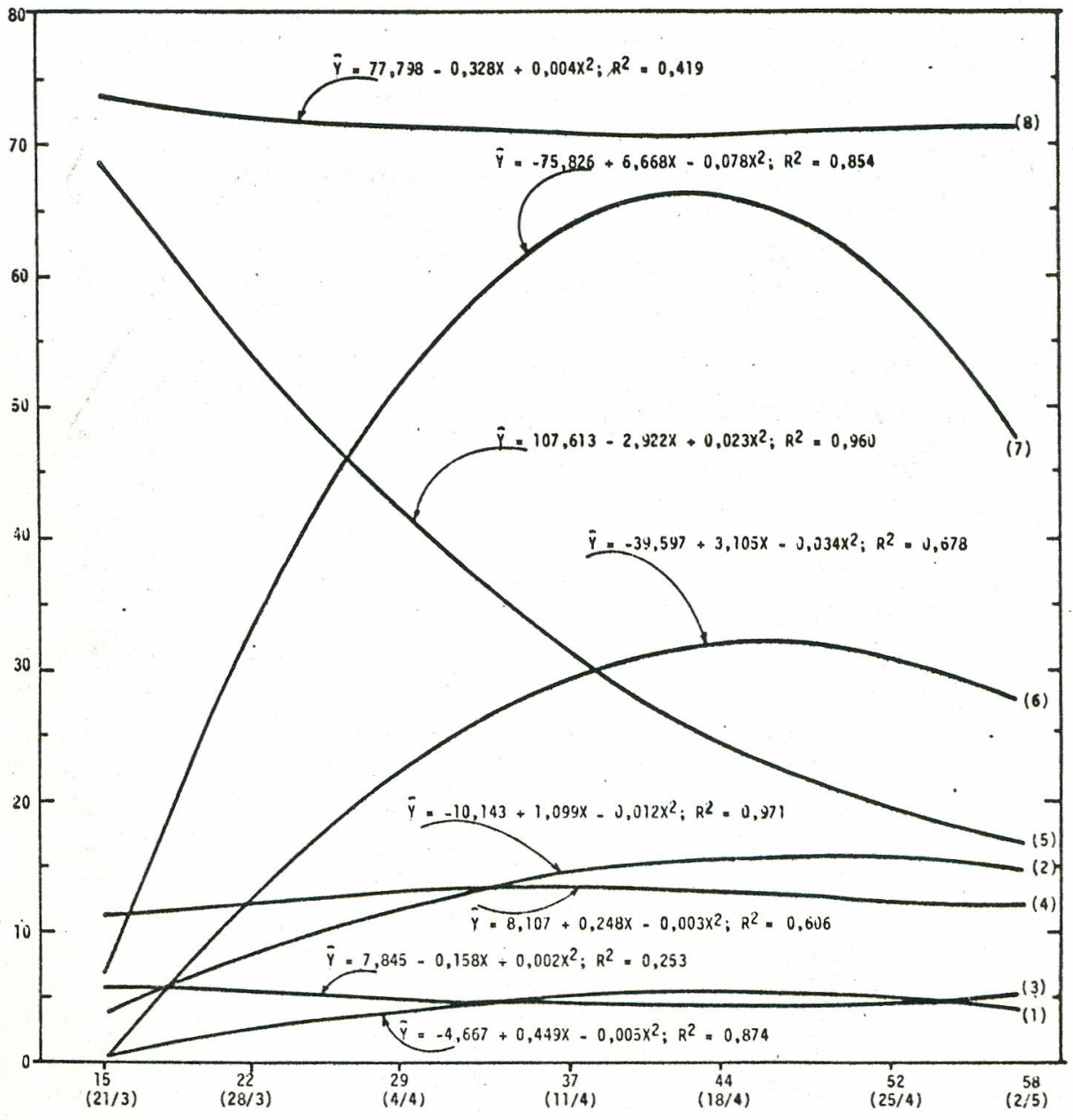

Dias após o florescimento e data de colheita

FIG. 1 - Indice de velocidade de emergência (1), peso de 1.000 sementes, em gramas (2) e porcentageǹs de: açúcares extraídos (3), fibra (4), umidade da semente (5), envelhecimento precoce (6), germinação (7) e extração do caldo (8), em função de 7 épocas de colheita de sorgo sacarino. Cultivar BR 501. Ano 1985. 


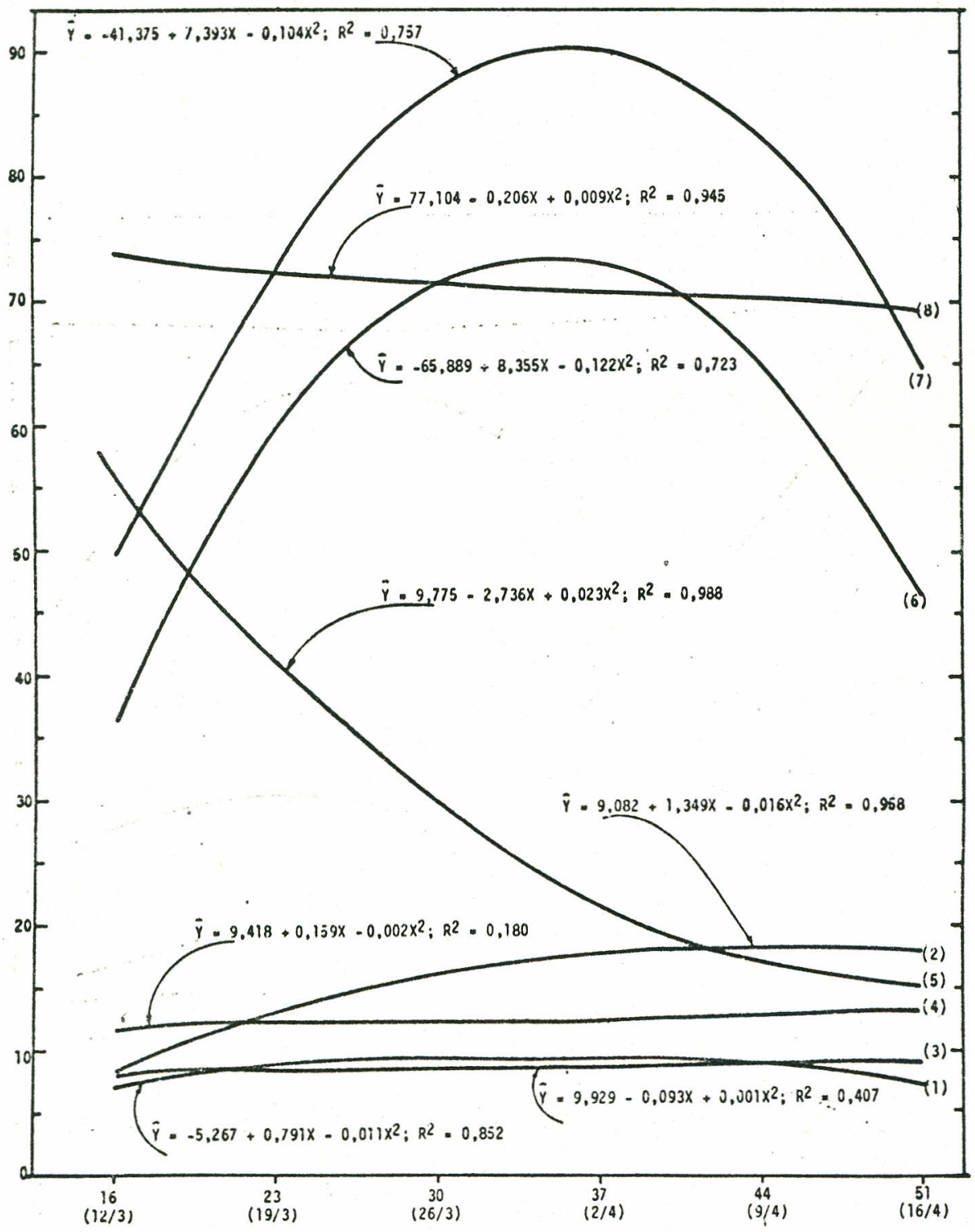

Dias apös o florescimento e data de colheita

FIG. 2 - Indice de velocidade de emergencia (1), peso de 1.000 sementes, em gramas (2) e porcentagens de: açúcares extraidos (3), fibra (4), umidade da semente (5), Hoppe (6), germinação (7) e extração do caldo (8), em função de 6 épocas de colheita de sorgo sacarino. Cultivar BR 501. Ano 1986. 


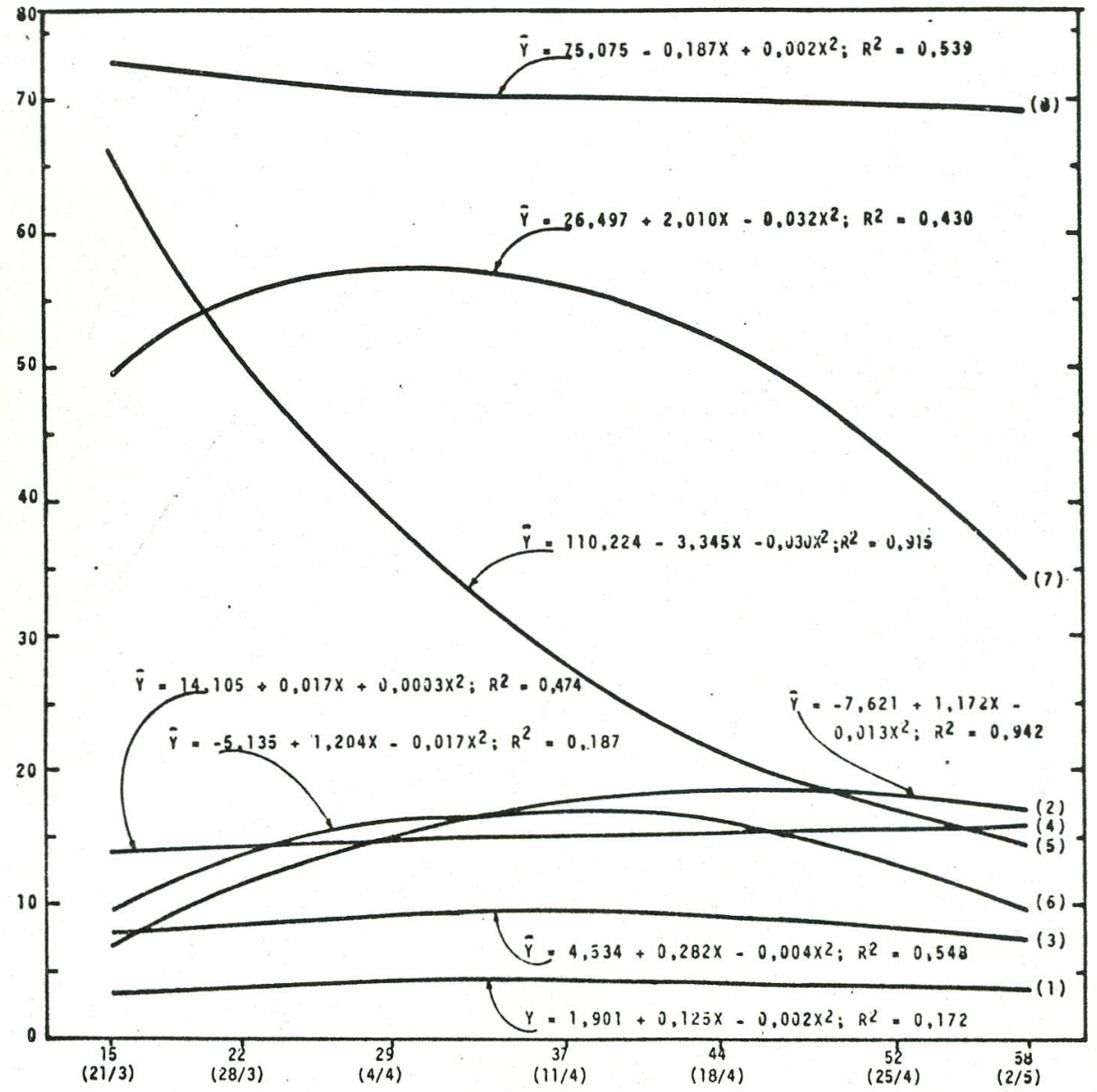

Dias apōs o florescimento e data de colheita

FIG. 3 - Indice de velocidade de emergência (1), peso de 1.000 sementes, em gramas (2) e porcentagens de: açúcares extraídos (3), fibra (4), umidade da semente (5), envelhecimento precoce (6), germinação (7) e extração do caldo (8), em função de 7 épocas de collheita de sorgo sacarino. Cultivar BR 503. Ano 1985. 


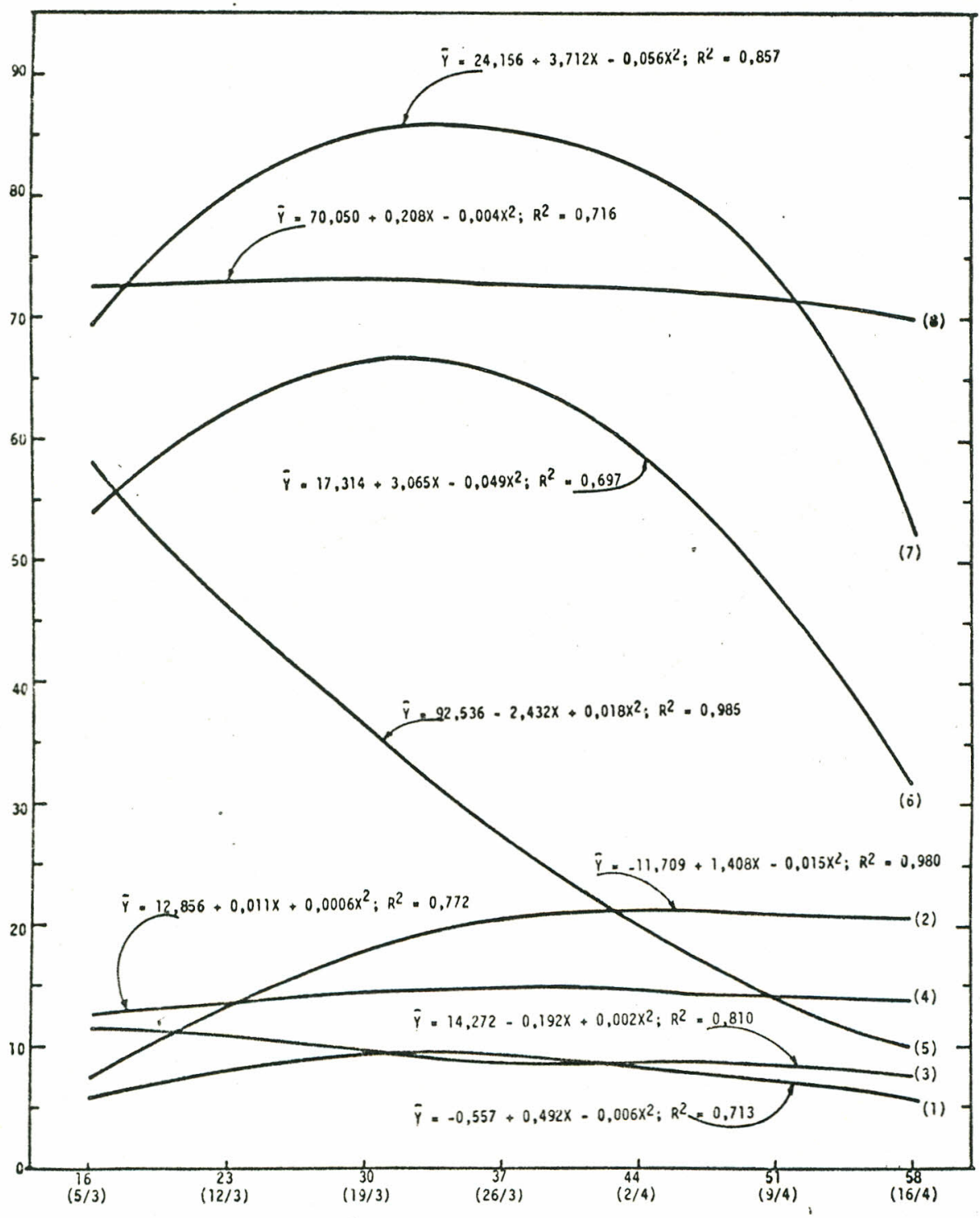

Dias após o florescimento e data de colheita

FIG. 4 - Indice de velocidade de emergência (1), peso de 1.000 sementes, em gramas (2) e porcentagens de: açúcares extraídos (3), fibra (4), umidade da semente (5), Hoppe (6), germinação (7) e extração do caldo (8), em função de 7 épocas de colheita de sorgo sacarino. Cultivar BR 503. Ano 1986.

Revista Brasileira de Sementes - Ano 10 - n? 3-Brasilia-DF - 1988 


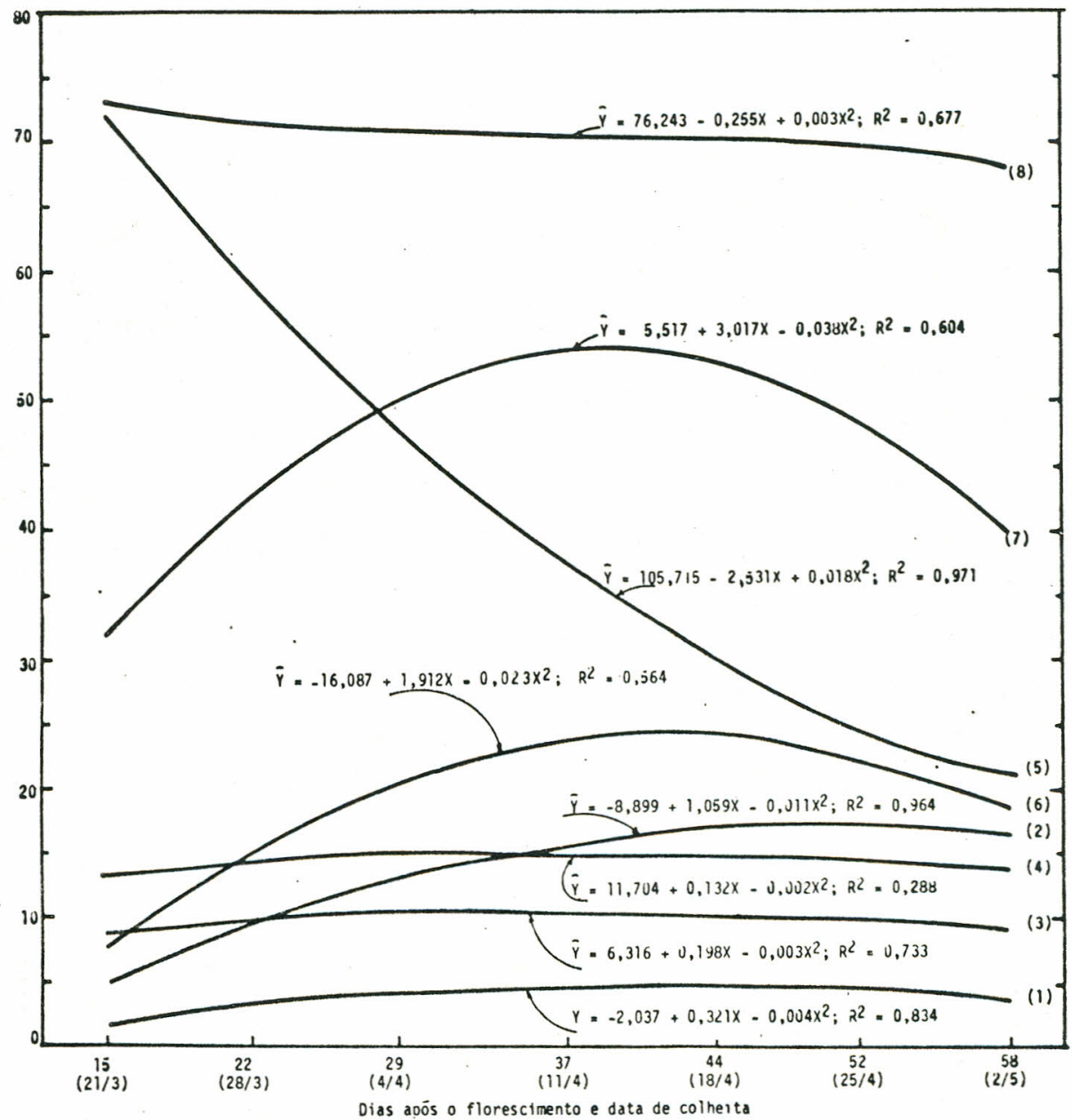

FIG. 5 - Indice de velocidade de emergência (1), peso de 1.000 sementes, em gramas (2) e porcentagens de: açúcares extraídos (3), fibra (4), umidade da semente (5), envelhecimento precoce (6), germinação (7) e extração do caldo (8), em função de 7 épocas de colheita de sorgo sacarino. Cultivar B R 505. Ano 1985. 


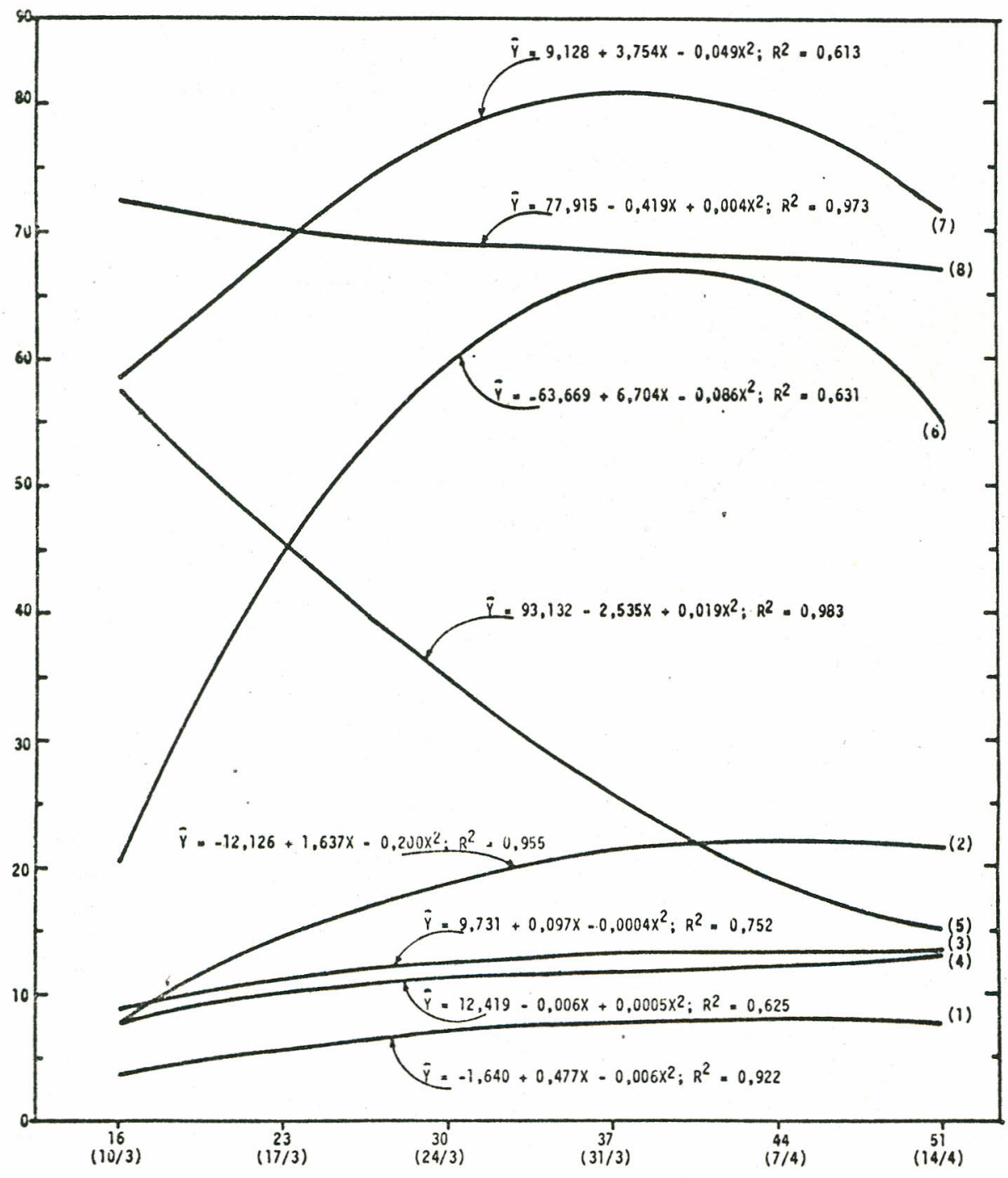

Dias apös o florescimento e data de colheita

FIG. 6 - Indice de velocidade de emergência (1), peso de 1.000 sementes, em gramas (2) e porcentagens de: açúcares extraídos (3), fibra (4), umidade da semente (5), Hoppe (6), germinação (7) e extração do caldo (8), em função de 6 épocas de colheita de sorgo sacarino. Cultivar BR 505. Ano 1986. 
Os maiores valores para as variáveis extração do caldo, germinação, envelhecimento precoce ou Hoppe, umidade da semente, peso de 1.000 sementes, fibra, açúcares extraídos e velocidade de emergência, foram obtidos quando as sementes estavam com umidade em torno de $30 \%$ correspondendo ao intervalo de 35 a 44 dias após o início do florescimento (Figuras 1 a 6).

Maior perda de umidade pelas sementes ocorreu nas primeiras épocas de colheita, estabilizando-se nas últimas (à partir da 5 a época) quando a umidade acusava índices próximos dos $20 \%$. Estes resultados estão em concordância a aqueles reportados por Sales (1978), que trabalhando com a cultivar NK-233, encontrou no 5 ? dia após a fertilização uma umidade de $80,7 \%$. Esta umidade decresceu rapidamente até 29 . dia após a antese atingindo $37,1 \%$. A partir deste estágio, a umidade da semente decresceu numa velocidade mais constante estabelecendo o equilibrio com o ambiente no 49 ? dia após a fecundação com uma umidade ao redor de $20 \%$.

Sementes colhidas prematuramente, com 15 ou 16 dias após a antese atingiram germinação de até $70 \%$. Kersting et al. (1961), conseguiram germinação em sementes de sorgo, cultivar Combine Kafir-60, no 12 ? dia após a fertilização. Aos 15 dias ou acima deste estágio, a germinação oscilou de ano para ano de 78 a $94 \%$ e de 71 a $95 \%$, respectivamente.

Embora a germinação tenha alcançado $70 \%$, o seu vigor medido pelo teste de envelhecimento precoce ou Hoppe e índice de velocidade de emergência foi baixo, podendo ser explicado por apresentar as sementes neste estágio, um pequeno acúmulo de matéria seca, portanto, imaturas fisiologicamente. E sabido que sementes imaturas são inçapacitadas de produzirem plantas vigorosas quando comparadas com aquelas fisiologicamente maduras.

$\mathrm{O}$ peso de 1.000 sementes, como já era esperado, apresentou in dices mais baixos quando as sementes ain da estavam no estádio leitoso. A medida que as sementes acumulavam matéria seca, o seu peso aumentava, estabilizando-se ao redor dos 44 dias após o início do florescimento. Resultados semelhantes foram reportados por Kersting et al. (1961), onde o máximo peso da matéria seca das sementes foi obtido aos 45 dias após a antese e umidade de $33 \%$.

Sementes das três cultivares de sorgo apresentaram, após a maturida de fisiológica, uma perda rápida e acentuada na germinação e no vigor, tendo sido mais severa no ano de 1985. Nota-se que maiores índices de germinação e vigor (envelhecimento precoce e índice de velocidade de emergência) foram obtidos no ano de 1986 (Figuras 1 a 6). 0 ano de 1985 foi mais chuvoso e com umidade relativa mais elevada durante o período de colheita, o que causou uma maior deterioração nas sementes ainda no campo (Tabela 1). Os valores determinados de maturação fisiológica do colmo de sorgo sacarino, extração do caldo, fibra e açúcares extraídos, apresentaram resultados semelhantes entre si durante os dois anos de experimento, isto é, vo com variaçбes muito pequenas durante todas as épocas de collheita, não chegando a 
afe tar o período útil de industrialização do sorgo sacarino (PUI).

O PUI do sorgo sacarino é expresso pela quantidade de açúcares extraídos e o mínimo aceitável é de $80 \mathrm{~kg}$ de açúcares extraídos por tonelada de colmo (Schaffert, 1986). Com base neste critério, somente a cultivar BR 501 no ano de 1985 , não atingiu o PUI mínimo aceitável, o que pode ser explicado por ter sido esta cultivar, a que apresentou, um menor teor de açúcares extraídos. Além disso, por ter sido o ano de 1985 mais chuvoso do que 1986 provocou um adiluição dos açúcares diminuindo o teor de Brix e, em consequência, uma menor extração.

As demais cultivares apresentaram quantidades de açúcares extraídos acima do mínimo aceitável, em todas as épocas de colheita demonstrando ser estas mais apropriadas na utilização pelas microdestilarias na produção de álcool.

\section{CONCLUSOES}

1. Os maiores índices de germinação e vigor, foram obtidos quando as semen. tes estavam com a umidade em torno de $30 \%$, correspondendo ao intervalo de 35 a 44 dias após o início do florescimento.

2. Sementes colhidas prematuramente, em tomo de 15 dias após a antese, atingiram o poder germinativo de até $70 \%$.

3. Todas as cultivares com exceção da BR 501, no ano de 1985, apresentaram rendimentos de açúcares extraídos superiores a $8 \%$, que é considerado o mínimo aceitável na in dustrialização do sorgo sacarino.

4. As cultivares BR 503 e BR 505 apresentaram-se mais apropriadas para produção de álcool.

5. As panículas das três cultivares de sorgo sacarino estudados podem ser utilizadas para sementes quando a sua umidade estiver próxima de $30 \%$. Neste estágio, houve maior índice de extração de açúcar e maior peso de 1.000 sementes. Portanto foi neste período que ocorreu a maturidade fisiologica do colmo e da semente.

\section{REFERENCIAS}

BRASIL. Ministério da Agricultura. Secretaria Nacional de Defesa Agropecuária. Regras para análise de sementes. Brasilia, 1980, 188p.

HOPPE, P.E. Cold testing for seed corn. Wisconsin Agriculture Experiment Station Bull. 507, 1955. 1.5.

KERSTING, J.F.; STICKLER, F.C. \& PAULI, A.W. Grain sorghum caryopsis development. I. Changes in dry weight, moisture percentage and viability. Agron. Journal. 53:36-37. 1961.

Revista Brasileira de Sementes - Ano $10-n$ ? 3-Brasilia-DF - 1988 
KOLEMAN, O.H. \& STOKES, 1.E. Storage studies of sorgo. Washington Agriculture Research Service. United States Department of Agriculture. 1964. (Technical Bulletin, 1307).

MAGUIRE, J.D. Speed of germination-aid in selection and èvaluation for seedling emergence and vigor. Crop. Sci. 2(2):176-77. 1962.

MAITI, R.K.; RAJU, P.S. \& BIDINGER, F.R. Studies on germinability and some aspects fo pre-harvest physiology of sorghum grain. Seed Science \& Technology. 13(1):27-35. 1985 .

SALES, I.C. Maturação de sementes de sorgo (Sorghum bicolor (L.) Moench). Universidade Federal de Pelotas, RS. 1978. 94p. (Dissertação de Mestrado).

SCHAFFERT, R.E. Determinação do periodo útil de industrialização para o sorgo sacarino. Relatório Técnico Anual do Centro Nacional de Pesquisa de Milho e Sorgo. 1980-1984. Sete Lagoas, MG, EMBRAPA/CNPMS. 1986. p. 155-157.

VENTRE, E.K. \& BYALL, S. Distribuition and variation with maturity of dissolved solids, sucrose and titratable acidity in the sorghum stalk. Joumal of Agricultural Research. 55(8):553-62, 1937.

ZINK, E. Vigor em semenes de milho. In: Seminário Brasileiro de Sementes, 2, Pelotas. Anais S.I.A. 1968. p. 231-32. 